\title{
Multicenter evaluation of dynamic three- dimensional whole-heart myocardial perfusion imaging for the detection of coronary artery disease defined by fractional flow reserve
}

Robert Manka ${ }^{1,2^{*}}$, Rolf Gebker ${ }^{3}$, Lukas Wissmann ${ }^{2}$, Roy Jogiya ${ }^{4}$, Manish Motwani ${ }^{5}$, Michael Frick ${ }^{6}$, Sebastian D Reinartz ${ }^{6}$, Bernhard Schnackenburg ${ }^{3}$, Eike Nagel $^{4}$, Sven Plein ${ }^{5}$, Sebastian Kozerke ${ }^{2,4}$

From 16th Annual SCMR Scientific Sessions

San Francisco, CA, USA. 31 January - 3 February 2013

\section{Background}

Cardiac magnetic resonance (CMR) perfusion imaging yields high diagnostic accuracy for the detection of coronary artery disease (CAD) [1]. However, standard 2D multislice CMR perfusion techniques only provide limited coverage and hence prohibit computation of myocardial ischemic burden. Recently, two single-center 3D CMR perfusion studies have proven highly diagnostic for the detection of CAD relative to quantitative coronary angiography
(QCA) [2] and fractional flow reserve (FFR) [3]. The aim of our prospective multicenter study is to assess the diagnostic performance of 3D CMR perfusion imaging in comparison with FFR.

\section{Methods}

Five centers across Europe have been enrolled to acquire 3D CMR perfusion and FFR data in a total of 150 patients with suspected CAD. CMR 3D perfusion imaging employs

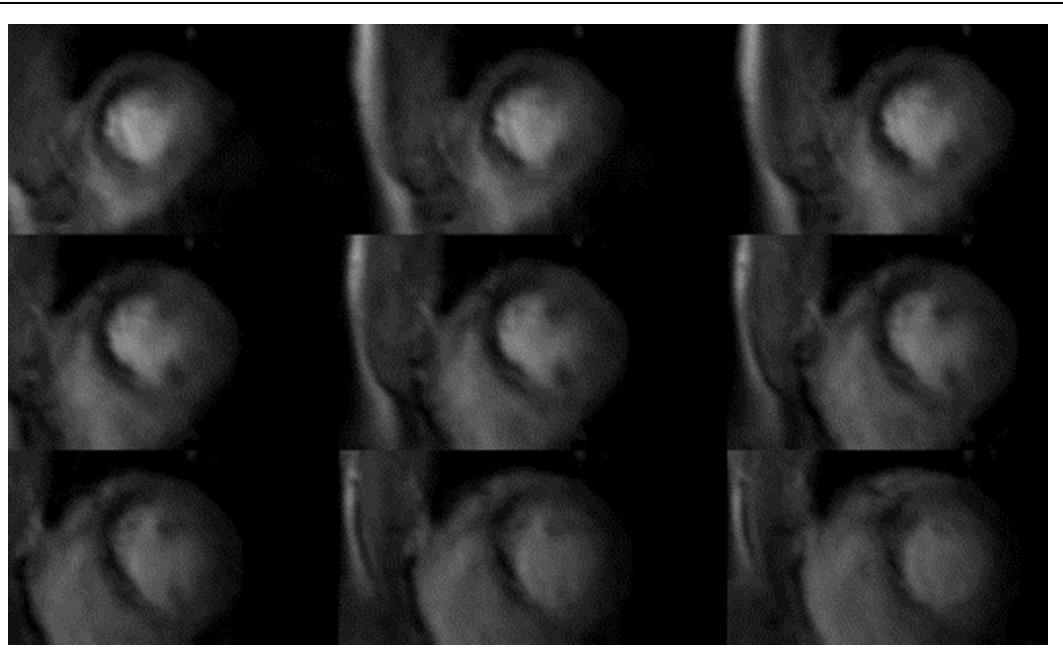

Figure $13-D$ CMR perfusion scans during adenosine stress showing a inducible perfusion deficit in anterior/anteroseptal segments extending from apical to basal slices. Invasive X-ray coronary angiogram demonstrated high-grade single-vessel disease with subtotal occlusion of the left anterior descending artery (LAD).

${ }^{1}$ University Hospital Zürich, Zürich, Switzerland

Full list of author information is available at the end of the article

(C) 2013 Manka et al; licensee BioMed Central Ltd. This is an Open Access article distributed under the terms of the Creative Commons 
10-fold accelerated k-t PCA [4] providing whole heart coverage with a spatial resolution of $2.3 \times 2.3 \times 5 \mathrm{~mm} 3$ on $3.0 \mathrm{~T}$ systems (Philips Healthcare, Best, The Netherlands). Perfusion scans were obtained under adenosine stress $(140 \mu \mathrm{g} / \mathrm{kg} / \mathrm{min}$ for $6 \mathrm{~min} ; 0.075 \mathrm{mmol} / \mathrm{kg}$ gadobutrol; Gadovist, Bayer Schering Pharma, Berlin, Germany) and at rest. FFR was recorded in all patent epicardial coronary arteries (significant stenosis $<0.75$ ). For visual analysis, 3D CMR perfusion scans were classified as pathologic if $\geq 1$ segment showed an inducible perfusion deficit with $>25 \%$ transmurality. Overall image quality of stress and rest 3D CMR perfusion scans was graded on a scale between 1 and 4 ( $1=$ non-diagnostic, $2=$ poor, $3=$ good, $4=$ excellent). All CMR perfusion analyses were performed in central core-lab, blinded to all clinical data.

\section{Results}

Here we report preliminary results obtained in the first 40 patients (mean age $63+/-11$ years, 11 female). CAD prevalence as defined by FFR $(<0.75)$ was $38 \%$ (15 of 40 patients). 3D CMR perfusion resulted in a sensitivity and specificity of $87 \%$ and $84 \%$, respectively. The mean visual score of $3 \mathrm{D}$ perfusion imaging was $3.4 \pm 0.7$ during adenosine stress and $3.6 \pm 0.5$ at rest $(p=0.06)$. No study was graded as non-diagnostic.

\section{Conclusions}

In this preliminary assessment of a sub cohort of our multicenter study 3D CMR perfusion imaging proved highly diagnostic for the detection of functionally significant CAD as defined by FFR. Analysis of the remaining data is required to fully conclude on the finding presented here.

\section{Funding}

Swiss National Science Foundation, grant \#CR3213_ 132671/1, Bayer Schering Pharma, Zürich Switzerland.

\footnotetext{
Author details

${ }^{1}$ University Hospital Zürich, Zürich, Switzerland. ${ }^{2}$ Institute for Biomedical Engineering University and ETH zürich, Zürich, Switzerland. ${ }^{3}$ German Heart Institute, Berlin, Germany. ${ }^{4}$ King's College London, London, UK. ${ }^{5}$ University of Leeds, Leeds, UK. 'University Hospital RWTH Aachen, Aachen, Germany.

Published: 30 January 2013

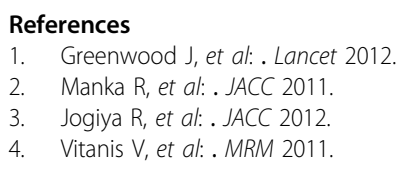

doi:10.1186/1532-429X-15-S1-0103

Cite this article as: Manka et al:: Multicenter evaluation of dynamic three-dimensional whole-heart myocardial perfusion imaging for the detection of coronary artery disease defined by fractional flow reserve. Journal of Cardiovascular Magnetic Resonance 2013 15(Suppl 1):0103.
}

\section{Submit your next manuscript to BioMed Central} and take full advantage of:

- Convenient online submission

- Thorough peer review

- No space constraints or color figure charges

- Immediate publication on acceptance

- Inclusion in PubMed, CAS, Scopus and Google Scholar

- Research which is freely available for redistribution

Submit your manuscript at www.biomedcentral.com/submit 